\title{
Effects of shifts in the rate of repetitive stimulation on sustained attention
}

\author{
JUDITH E. KRULEWITZ \\ Iowa State University, Ames, Iowa 50010 \\ and \\ JOEL S. WARM and THEODORE H. WOHL \\ University of Cincinnati, Cincinnati, Ohio 45221
}

\begin{abstract}
The effects of shifts in the rate of presentation of repetitive neutral events (background event rate) were studied in a visual vigilance task. Four groups of subjects experienced either a high $(21 \mathrm{events} / \mathrm{min})$ or a low $(6$ events $/ \mathrm{min}$ ) event rate for $20 \mathrm{~min}$ and then experienced either the same or the alternate event rate for an additional $40 \mathrm{~min}$. The temporal occurrence of critical target signals was identical for all groups, irrespective of event rate. The density of critical signals was 12 signals $/ 20 \mathrm{~min}$. By the end of the session, shifts in event rate were associated with changes in performance which resembled contrast effects found in other experimental situations in which shift paradigms were used. Relative to constant event rate control conditions, a shift from a low to a high event rate depressed the probability of signal detections, while a shift in the opposite direction enhanced the probability of signal detections.
\end{abstract}

In most sustained attention or vigilance experiments, a simple motor response is required to a signal which appears within a matrix of regularly occurring neutral background events. The frequency of presentation of neutral events, or the background event rate. is a salient factor in determining performance efficiency. Detection probability for critical signals is inversely related to the number of neutral events that the subject nust monitor in search of these signals (Mackworth, 1970a). Moreover, the effects associated with other factors such as signal amplitude, frequency, and regularity are modified by variations in the matrix of neutral events in which critical signals are embedded (Metzger, Warm, \& Senter, 1974; Moore \& Gross, 1973; Warm \& Alluissi. 1971). Evidently, background event rate is a prepotent stimulus paraneter in sustained attention and a thorough knowledge of the phenomena associated with variations in the rate of presentation of neutral events is necessary for the development of a comprehensive psychophysics of vigilance (e.g., Loeb \& Alluisi, 1970).

To date. all of the experiments which have been concerned with variations in event rate have exposed subjects to a continuous schedule of neutral signal presentations. No attempt has been made to assess the

This research was sponsored by the Institute of Space Sciences of the University of Cincinnati under National Aeronautics and Space Administration Grant NGL-36-004-014 and by the Department of Health, Education, and Welfare in conjunction with the Cincinnati Center for Developmental Disorders through Project Nos. 912 and 918. The authors are indebted to Drs. H. D. Fishbein, D. A. Schumsky, and M. Schwartz for their helpful comments. Requests for reprints should be sent to Judith E. Krulewitz, Department of Psychology, lowa State University, Ames, Iowa 50010. effects of a shift in event rate during the session on performance efficiency. The present study focuses on this problem. Shift paradigms have been used in a variety of other experimental situations to establish the residual effects of one set of stimulus conditions upon performance under a different set of conditions (Broadbent, 1971; Hulse, Deese, \& Egeth, 1975). The identification of the residual effects of exposure to one event rate on subsequent performance under a different event rate can permit inferences regarding the role played by the subject's immediate prior history in his susceptability to the effects of event rate. Furthermore, this line of investigation also has theoretical justification.

One approach toward explaining the effects of variations in event rate is represented by Mackworth's $(1968,1970 \mathrm{a}, \mathrm{b})$ habituation model of vigilance. This position maintains that the repetitive stimulation of the recurring background events serves to habituate neurophysiological responses which, in turn, degrades the subject's ability to detect critical signals. Due to the frequency of repetition, habituation accumulates more rapidly under a high, relative to a low, event rate, leading to poorer overall performance under the high event rate.

Another" approach to account for event rate differences is in terms of expectancy theory (Colquhoun, 1961). When critical signal density is held constant, increments in event rate reduce the conditional probability that a given stimulus event is a critical signal. Thus, superior performance under a low, relative to a high, event rate is due to the subject's greater expectancy that any stimulus even: will be a critical signal in the low event rate condition. As is the case with most theories of vigilance, it is 
difficult to construct a direct empirical test between these points of view. One means of attacking this problem experimentally, however, is through the use of a shift paradigm in which event rates are altered in a low-to-high and in a high-to-low direction during the vigilance session. Mackworth states plainly that any change in stimulus conditions produces dishabituation which should result in improved performance $(1968$, p. $316 ; 1970$ b, p. 195). Shifts in event rate represent a drastic change in stimulus conditions. Therefore, Mackworth's position leads to the expectation of superior performance for shifted subjects relative to nonshifted controls at both a low and a high postshift event rate.

An expectancy approach leads to different predictions. In a series of experiments which have provided strong evidence for the role of expectancy in sustained attention tasks, Colquhoun and Baddeley (1964, 1967) have indicated that the frequency of signal detections in a test phase was directly related to the conditional probability of critical signals to which subjects were exposed during an adapting phase. Consequently, the expectancy position suggests that at a high postshift event rate (low ongoing conditional probability), subjects shifted from a low event rate (high initial conditional probability) should detect more signals than nonshifted controls. By contrast, at a low postshift event rate (high ongoing conditional probability), subjects shifted from a high event rate (low initial conditional probability) should detect fewer signals than nonshifted controls. These possibilities were explored in the present study.

\section{METHOD}

\section{Subjects}

Seventy-two undergraduates, 36 men and an equal number of women, from the University of Cincinnati served as subjects. None had participated previously in any vigilance study.

\section{Design \\ All subjects participated in a 1-h session divided into three 20-min periods of watch. The subjects experienced either a high (21 events $/ \mathrm{min}$ ) or a low ( 6 events $/ \mathrm{min}$ ) background event rate during the initial period (preshift phase) and then experienced either the same or the alternate event rate during the remaining two periods (postshift phase). Thus, the four experimental conditions were $\mathrm{HH}$ (high-high), HL (high-low), LL (low-low), and LH (low-high), Eighteen subjects were assigned at random to each of these conditions, with the restriction that gender be equal across groups.}

\footnotetext{
Apparatus

The subjects monitored the movement of an $18 \times 2 \mathrm{~mm}$ bar of red light, which appeared within an $18 \times 32 \mathrm{~mm}$ window centered within a $61 \times 61 \mathrm{~cm}$ flat-black panel. Apparent movement of the light bar was produced by successively illuminating small, and appropriately spaced, diffusing screens. A neutral event, to which no overt response was required, was a pair of movements in which the bar moved $24 \mathrm{~mm}$ to the right (movement time, $0.60 \mathrm{sec}$ ), snapped back to its start position (where it remained for $0.80 \mathrm{sec}$ ), again moved $24 \mathrm{~mm}$ to the right (movement time, $0.60 \mathrm{sec}$ ), and snapped back to its start position, where it remained for the ensuing interevent interval. High and low event rates of 21 and 6 events $/ \mathrm{min}$
}

were produced by setting the interevent intervals at 0.90 and 9.60 sec, respectively. Critical signals for detection were increases in the second deflection within a pair of movements. In critical signals, the second detlection was $30 \mathrm{~mm}$ instead of $24 \mathrm{~mm}$. This represented an increment of $25 \%$ of the base movement. With a two-alternative forced-choice psychophysical procedure, critical signals were essentially always detected by alerted subjects under both the high and the low event rates. The subject indicated his or her detection of a critical signal by pressing a hand-held microswitch. The light bar display was similar to that used by Jerison and his co-workers (Jerison \& Pickett, 1964; Jerison, Pickett. \& Stenson, 1965) in a series of experiments which has been cited frequently by Mackworth (1970a), in describing event rate effects. It is designed to minimize memory demands as to the nature of a critical signal by having all the information needed to make a paired-comparison judgment available within an event.

Twelve critical signals were presented during each period of watch in all experimental conditions. Intersignal intervals ranged from 30 to $400 \mathrm{sec}$. with a mean of $100 \mathrm{sec}$. They were randomly ordered for each subject during each of the three 20 -min periods. Stimulus event rates and the occurrence of critical signals were controlled by solid-state programming equipment and a Gerbrand's punched-tape timer. The subject's responses were recorded on two ITT electronic counters. Responses occurring within $2.5 \mathrm{sec}$ after the onset of critical signals were recorded automatically as correct detections; all others were considered as errors of commission or false alarms. The 2.5-sec cutoff value was used because extensive pilot work and a previous experiment with the display employed in this study (Metzger, Warm, \& Senter, 1974) indicated that if a subject was going to respond to a critical signal at all, he would do so within a $2.5-\mathrm{sec}$ limit.

\section{Procedure}

Each subject was tested individually in a $1.5 \times 1.5 \times 2.1 \mathrm{~m}$ acoustically treated experimental chamber. The walls of the chamber were painted flat white, and ambient illumination of $4.5 \mathrm{fL}$ was provided by a light source mounted in a cylindrical ceiling fixture. The monitored display was mounted at eye level in a wall of the chamber. Subjects were seated without restraint and viewed the display from a distance of $86 \mathrm{~cm}$. All subjects wore Soundbarrier earmuffs, which, together with the noise of an exhaust fan, served to attenuate random laboratory sounds. The vigil proceeded from preshift to postshift phases without interruption and, except for alterations in event rate, there was no discriminable change between periods. Subjects in the shift condition were not instructed as to the possibility of a change in event rates and did not anticipate such changes. All subjects surrendered their watches at the start of the session and had no knowledge of the length of the vigil other than that it would not exceed $2 \mathrm{~h}$.

\section{RESULTS}

The percentage of correct detections was calculated from the data of each subject for each 20-min period of watch. Mean percentages of correct detections for the four experimental groups are plotted in Figure 1 as a function of periods of watch.

\section{Preshift Phase}

The figure shows that detection probability during the initial 20 -min period of watch was greater under the low, relative to the high, event rate. Moreover, during this phase, the scores for groups experiencing the same background event rate $(\mathrm{HH}$ and $\mathrm{HL} ; \mathrm{LL}$ and LH) were almost identical. The data of the preshift 
phase were converted to arcsines and subjected to a 2 (event rate) by 2 (shift potential) analysis of variance. The only significant difference was between event rates, $F(1,68)=16.88, p<.001$. The absence of a signiticant main effect for shift potential $(F<1)$, together with a nonsignificant Event Rate by Shift Potential interaction ( $F<1$ ), confirms that, within event rates, the two shift potential groups had a common origin.

\section{Postshift Phase}

It is evident in Figure 1 that, during this phase of the study, the detection scores for the nonshifted control groups ( $\mathrm{LL}$ and $\mathrm{HH}$ ) remained substantially at their preshift levels. On the other hand, the figure shows that a shift in event rate was associated with a marked change in performance efficiency. Detection scores for the group shifted in the low-to-high direction (LH) dropped below their preshift level and tended to fall continuously during the two periods following the shift. By contrast, the scores for the group shifted in the high-to-low direction (HL) rose above their preshift level and tended to increase consistently across the two postshift periods.

The residual effects of the initial event rate to which the subjects were exposed on subsequent performance under a new event rate were examined by comparing the shifted with the nonshifted groups at each ongoing event rate of the postshift phase. In order - to accomplish this, the data of the postshift phase were converted to arcsines and subjected to a 2 (ongoing event rate) by 2 (event rate shift) by 2 (periods) analysis of variance. Detection efficiency during the postshift phase was greatest when the ongoing event rate was low, $F(1,68)=33.08, \mathrm{p}<.001$, and, in general. performance efficiency declined over time on watch, $F(1,68)=4.51, p<.05$. The main effect for event-rate shift and all single-order interactions in the analysis lacked significance $(p>.05)$. There was, however, a significant second-order interaction between ongoing event rate. event rate shift, and periods, $\mathrm{F}(1,68)=9.64, \mathrm{p}<.005$.

This significant interaction indicates that the preshift event rate did exert a differential effect upon postshift performance. In order to clarify the nature of this interaction, postmortem $F$ tests (Kirk, 1968) were computed between the scores of the shifted group and the nonshifted control group at each event rate during the early and late portions of the postshift phase. During the first postshift period, no significant differences were noted between the shifted and the nonshifted group at either event rate, $F<1$ in both cases. On the other hand, during the second postshift period, the group shifted in the low-to-high direction (LH) detected signiticantly fewer signals than the nonshifted control group $(\mathrm{HH}), F(1,136)=4.74$, $\mathrm{p}<.05$. As is evident in Figure 1, the group shifted in

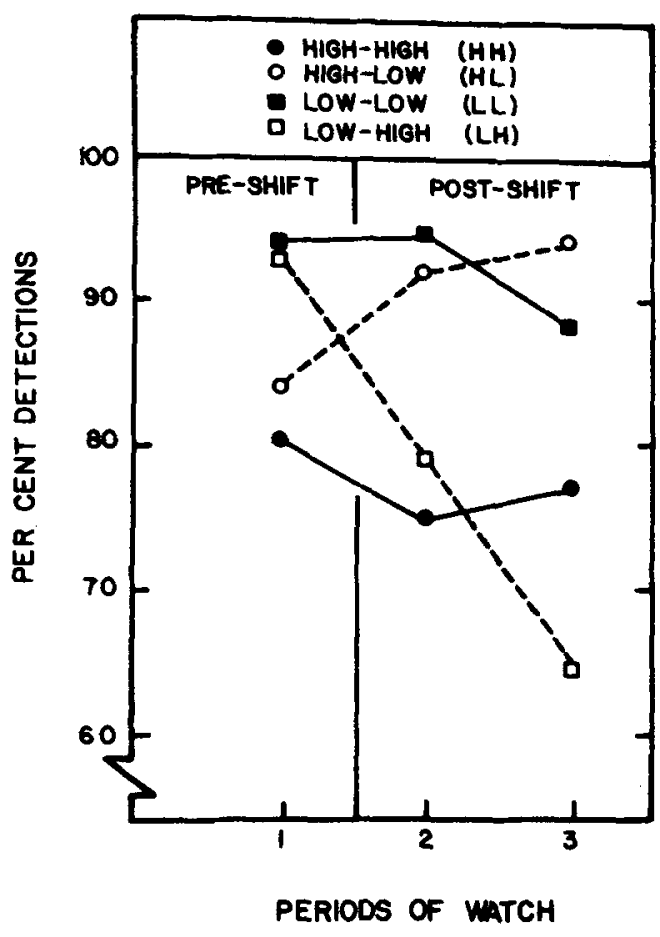

Figure 1. Percentage of correct detections as a function of periods of watch $[20 \mathrm{~min}]$ for the high and low background event-rate conditions. Data for the preshift and postshift phases of the study are plotted separately in each panel. The nonshift groups are indicated by filled figures and solid lines; the shift groups are indicated by open figures and dasbed lines.

the high-to-low direction (HL) tended to detect more signals late in the postshift phase than did the nonshifted control group (LL). While this difference did not reach statistical significance, $F(1,136)=$ 1.23. $\mathrm{p}>.05$, an examination of Figure 1 reveals that the performance of Group HL during this portion of the experiment equaled that of the low-event-rate groups during the preshift phase of the study. It is likely, therefore, that further improvement in Group HL was limited by a ceiling effect.

Inspection of Figure 1 reveals that in relation to the overall difference between event rates, differences between the shifted groups and the nonshifted controls were not large. In order to reinforce the conclusions based upon the means in Figure 1, comparisons were made of the direction of change for individual subjects across periods. The number and percentage of subjects showing an increment, decrement. or no change in detection scores for Periods 1 vs. 2,1 vs. 3 , and 2 vs. 3 are presented in Table 1.

The data of Table 1 support those in Figure 1. In all cases, the distributions with respect to changes in performance coincide with the direction of effects evidenced by the means in the figure. ${ }^{1}$ 
Table 1

The Number and Percentage of Subjects in Each Group Showing Increments, Decrements, or No Change in Detection Probability in Comparisons of Periods 1 vs. 2,1 vs. 3, and 2 vs. 3

\begin{tabular}{|c|c|c|c|c|c|c|c|}
\hline \multirow[b]{3}{*}{ Group* } & \multirow[b]{3}{*}{$\begin{array}{l}\text { Direction } \\
\text { of Change }\end{array}$} & \multicolumn{6}{|c|}{ Periods Compared } \\
\hline & & \multicolumn{2}{|c|}{1 vs. 2} & \multicolumn{2}{|c|}{1 vs. 3} & \multicolumn{2}{|c|}{2 vs. 3} \\
\hline & & No. & $\begin{array}{l}\text { Per- } \\
\text { cent }\end{array}$ & No. & $\begin{array}{l}\text { Per- } \\
\text { cent }\end{array}$ & No. & $\begin{array}{l}\text { Per- } \\
\text { cent }\end{array}$ \\
\hline HH & $\begin{array}{l}\text { Increase } \\
\text { Decrease } \\
\text { No Change }\end{array}$ & $\begin{array}{l}4 \\
9 \\
5\end{array}$ & $\begin{array}{l}22 \\
50 \\
28\end{array}$ & $\begin{array}{r}5 \\
11 \\
2\end{array}$ & $\begin{array}{l}28 \\
61 \\
11\end{array}$ & $\begin{array}{l}6 \\
9 \\
3\end{array}$ & $\begin{array}{l}33 \\
50 \\
17\end{array}$ \\
\hline HL & $\begin{array}{l}\text { Increase } \\
\text { Decrease } \\
\text { No Change }\end{array}$ & $\begin{array}{l}9 \\
2 \\
7\end{array}$ & $\begin{array}{l}50 \\
11 \\
39\end{array}$ & $\begin{array}{r}11 \\
2 \\
5\end{array}$ & $\begin{array}{l}61 \\
11 \\
28\end{array}$ & $\begin{array}{r}5 \\
3 \\
10\end{array}$ & $\begin{array}{l}28 \\
17 \\
56\end{array}$ \\
\hline $\mathbf{L L}$ & $\begin{array}{l}\text { Increase } \\
\text { Decrease } \\
\text { No Change }\end{array}$ & $\begin{array}{r}4 \\
3 \\
11\end{array}$ & $\begin{array}{l}22 \\
17 \\
61\end{array}$ & $\begin{array}{l}3 \\
6 \\
9\end{array}$ & $\begin{array}{l}17 \\
33 \\
50\end{array}$ & $\begin{array}{r}1 \\
7 \\
10\end{array}$ & $\begin{array}{r}6 \\
39 \\
56\end{array}$ \\
\hline LH & $\begin{array}{l}\text { Increase } \\
\text { Decrease } \\
\text { No Change }\end{array}$ & $\begin{array}{r}1 \\
14 \\
3\end{array}$ & $\begin{array}{r}6 \\
78 \\
17\end{array}$ & $\begin{array}{r}0 \\
17 \\
1\end{array}$ & $\begin{array}{r}0 \\
94 \\
6\end{array}$ & $\begin{array}{r}1 \\
14 \\
3\end{array}$ & $\begin{array}{r}6 \\
78 \\
17\end{array}$ \\
\hline
\end{tabular}

*Data for all groups based upon $N=18$.

\section{DISCUSSION}

Consistent with previous investigations, the overall percentage of signals detected in this study was inversely related to the rate of presentation of neutral background events. Furthermore, a shift in event rate produced a marked change in performance efficiency, which depended, in part, upon the event rate to which the subject was exposed immediately prior to the shift. It is important to keep in mind that shifts in event rate were not accompanied by any variations in the physical nature or the density of critical signals, or by changes in the temporal course of critical signal appearances. Only the frequency of neutral events and the subject's prior exposure to neutral events were systematically varied between groups. Therefore, the present results constitute a further and a dramatic demonstration of the potent influence of the event-rate context on signal detectability in the vigilance task.

As noted earlier, the habituation and expectancy theories of vigilance lead to different predictions regarding the effects of a shift in event rate on performance efficiency. However, neither of these positions can easily account for the outcome of this investigation.

Predictions from Mackworth's (1968, 1970a, b) habituation model were based on the assumption that changes in stimulus conditions associated with an increase or decrease in event rate would lead to dishabituation and, therefore, to superior performance for the shifted relative to the nonshifted groups at each postshift event rate. Contrary to expectations from the model, the scores for the group shifted in the low-to-high direction (LH) failed to exceed those of the nonshifted control group (HH) during the postshift phase. Instead, the performance of Group LH did not differ significantly from that of Group HH during the first postshift period, and it dropped significantly below that of the nonshifted control group during the second postshift period. This late-appearing deficit for Group LH is not predictable from a simple habituation position. Moreover, while the scores for the group shifted in the high-to-low direction (HL) tended to exceed those of the nonshifted control group (LL) during the postshift phase, they did so only after the shifted group had experienced the new event rate for $20 \mathrm{~min}$. According to Mackworth $(1968,1970 \mathrm{~b})$ and Thompson and Spencer (1966), habituated responses tend to dishabituate promptly following a change in stimulus conditions and to rehabituate after repeated exposure to a habituating stimulus. Therefore, the lateappearing superiority for Group HL does not seem to fit with current knowledge regarding the time course of dishabituation and rehabituation.

With regard to expectancy theory, the results do not coincide with Colquhoun and Baddeley's $(1964,1967)$ earlier findings regarding the residual effects of the conditional probability of critical signals. In their experiments, detection rates during the entire portion of a test phase were directly related to the conditional probability of critical signals which subjects encountered initially during an adapting phase. By contrast, the conditional probability of critical signals to which subjects were exposed initially in this study had little effect on performance during the early portion of the postshift phase, and, during the late portion of the postshift phase, the results were in opposite direction to those of Colquhoun and Baddeley; at both event rates, detection scores during the second postshift period were greater for subjects exposed initially to a condition of low, as compared to a high, conditional probability.

It is noteworthy, that the results during the latter portion of the postshift phase of this investigation resemble contrast effects which have been observed in other experiments where shift paradigms have been used (Hulse, Deese, \& Egeth, 1975). As in these other situations, subjects who were first exposed to a condition which led to good performance (low event rate in this case) did more poorly when shifted to a less favorable condition (high event rate) than did controls who were maintained on the less favorable condition throughout the experiment. At the same time, subjects who were first exposed to a condition which led to poor performance (high event rate in this case) tended to do better when shifted to a more favorable condition (low event rate) than controls who experienced the less favorable condition for the duration of the experiment.

The observation of contrast effects in the present data is interesting and potentially important; it links a 
characteristic of performance in a sustained attention task to that in a wide variety of situations in which subjects have had the opportunity to compare one set of stimulus conditions with another (Corso, 1967; Hulse, Deese, \& Egeth, 1975). A complete explanation of contrast effects in these other situations is complex and often requires the incorporation of a number of factors. Most likely, the present results also require a multifactored explanation.

One approach toward an understanding of the present findings may come from a suggestion by Jerison and his co-workers (Jerison \& Pickett, 1964; Jerison, Pickett, \& Stenson, 1965), that increments in event rate increase the demands placed upon the subject in a vigilance task by increasing the pace at which he must observe the monitored display. The result is a decline in his willingness to attend to the task and poorer performance. From this point of view, it is conceivable that an initial exposure to a low event rate served as a comparison anchor (e.g., Corso, 1967) which accentuated the apparent pace of observing for subjects in Group LH relative to those in Group $\mathrm{HH}$ and that such accentuation eventually led the subjects in the shifted group to "undershoot" the performance of those in the nonshifted control group. By the same token, an initial encounter with a high event rate may have diminished the apparent pace of observing for subjects in Group HL relative to those in Group LL, with the result that the performance of the shifted group ultimately tended to exceed that of the nonshifted controls.

Perhaps the most ubiquitous feature of performance in sustained attention experiments is the decrement function, or the tendency for detection rates to decline over time with nonchanging stimulus conditions (Broadbent, 1971; Mackworth, 1970a). This effect was not found in the present study; detection scores for the nonshifted control groups, LL and $\mathrm{HH}$, remained relatively stable over the 1 -h session. The absence of a decrement in Group $L L$ was not entirely unexpected, however. In the initial experiment with the type of display used in this study, Jerison and Pickett (1964) also failed to find a decrement in signal detectability at an event rate of 5 events $/ \mathrm{min}$-an event rate which is almost identical to that used in Group LL ( 6 events $/ \mathrm{min}$ ). On the other hand, they did find a decrement with an event rate of 30 events / $\mathrm{min}$ - an event rate that is somewhat higher than that used in Group HH ( 21 events/min). This implies that, with the type of display used in these experiments, event rate may be a crucial factor in determining the presence or absence of a decrement function and that an event rate of 21 events/min may not have been high enough to produce a decline in detection efficiency over time. This implication is consistent with recent findings by Levine, Romashko, and Fleishman (1973) that the decrement function in sustained attention tasks is dependent upon the perceptual abilities demanded by the task and the characteristics of the sensory field in which critical stimuli are embedded.

\section{REFERENCES}

Broadbent, D. E. Decision and stress. New York: Academic Press, 1971.

Colouhoun, W. P. The effect of "unwanted" signals on performance in a vigilance task. Ergonomics, 1961, 4, 41-52.

Colquhoun, W. P., \& Baddeley, A. D. Role of pretest expectancy in vigilance decrement. Journal of Experimental Psychology, 1964, 68, 156-160.

Colquhoun, W. P., \& Baddeley, A. D. Influence of signal probability during pretraining on vigilance decrement. Journal of Experimental Psychology, 1967, 73. 153.155.

Corso, J. F. The experimental psychology of sensory behavior. New York: Holt, Rinehart, \& Winston, 1967.

Hulse. S. H., DeEse, J., \& EGETH, H. The psychology of learning (4th ed.). New York: McGraw-Hill, 1975.

Jerison, H. J., \& Picketr, R. M. Vigilance: The importance of the elicited observing rate. Science, 1964, 143, 970-971.

Jerison, H. J., Picketr, R. M., \& Stenson, H. H. The elicited observing rate and decision processes in vigilance. Human Factors, 1965, 7, 107-128.

KIRK, R. E. Experimental design: Procedures for the behavioral sciences. Belmont. Calif: Wadşworth, 1968.

Levine. J. M.. Romashoo, T., \& Fleishman, E. A. Evaluation of an abilities classification system for integrating and generalizing human performance research findings: An application to vigilance tasks. Journal of Applied Psychology, 1973, 58, 149-157.

LOEB, M., \& Alluisi, E. A. Influence of display, task, and organismic variables on indicies of monitoring behavior. Acta Psychologica, 1970, 33, 343-366.

MACKWORTh, J. F. Vigilance, arousal, and habituation. Psychological Review', 1968, 75, 308-322.

MackWORTH, J. F. Vigilance and attention. Baltimore: Penguin, 1970. (a)

MACKWORTH, J. F. Vigilance and habituation. Baltimore: Penguin, 1970. (b)

MetzGer, K. R., WARM, J. S., \& SEnter, R. I. Effects of background event rate and critical signal amplitude on vigilance performance. Perceptual and Motor Skills, 1974, 38, 1175-1181.

Moore. S. F.. \& Gross, S. J. Influence of critical signal regularity, stimulus event matrix, and cognitive style on vigilance performance. Journal of Experimental Psychology, 1973. 99. 137-139.

THOMPSon, R. F., \& SPENCER, W. A. Habituation: A modal phenomenon for the study of neuronal substrates of behavior. Psychological Review, 1966, 73, 16-43.

WARM, J. S., \& Allusisi. E. A. Influence of temporal uncertainty and sensory modality of signals on watchkeeping performance. Journal of Experimental Psychology, 1971. 87. 303-308.

\section{NOTE}

1. In recent years, signal detection measures, $d^{\prime}$ and $\beta$, have become important indicies of vigilance performance (Broadbent. 1971). Such meaures could not be meaningfully applied to the present data because commissive errors were rare. The mean frequency of talse alarms across all experimental conditions was less than $1 \%$, and $46 \%$ of the subjects made one or no false alarms throughout the vigil. There was no systematic relation between the frequency of commissive errors and shifts in event rate.

(Received for publication December 20, 1974; revision received June 18, 1975.) 